\title{
Ferrioxamines $B$ and $E$ as iron sources for the marine diatom Phaeodactylum tricornutum
}

\author{
S. Soria-Dengg*, U. Horstmann \\ Institut für Meereskunde, Düsternbrooker Weg 20, D-24105 Kiel, Germany
}

\begin{abstract}
The utilization of iron from the trihydroxamate-type siderophores ferrioxamine B (FOB) and ferrioxamine $\mathrm{E}$ (FOE) by the marine diatom Phaeodactylum tricornutum was studied. Cells grown under iron-limiting conditions took up iron faster from FOE and FOB than from Fe-EDTA and FeCl ${ }_{3}$. Minimal iron uptake from the siderophores was observed for cells grown in media with sufficient iron. The uptake of iron from FOB was inhibited by the ferrous ion chelator, BPDS, evidence that a reductive pathway is involved in the uptake mechanism. On the other hand, iron uptake from FOE was not affected by BPDS, indicating that FOE may be taken up as an intact complex by the cell. Uptake kinetics show that FOE is transported faster into the cell than the iron from FOB. Growth experiments, however, indicated that $F O B$ is more efficient in supplying utilizable iron to the cell. The uptake mechanisms exhibited typical saturation kinetics, corresponding to the saturation of the transport ligand for FOE and of the reductive system for FOB. FOE transport yielded a lower $K_{\mathrm{m}}$ (half-saturation concentration) compared to FOB, indicating a more efficient 'true-siderophore' transport system. The results of our experiments suggest the existence of multiple pathway transport mechanisms for iron uptake from exogenous siderophores in P. tricornutum. The utilization of microbial siderophores by phytoplankton presents new aspects in bacteria-phytoplankton interaction.
\end{abstract}

KEY WORDS: Ferrioxamine B · Ferrioxamine E · Siderophores · Phaeodactylum tricornutum - Iron Phytoplankton

\section{INTRODUCTION}

The recent iron enrichment experiments performed in the equatorial Pacific have provided strong evidence that iron limitation controls phytoplankton productivity in this area (Kolber et al. 1994, Martin et al. 1994). This may also be true for other high nutrient low chlorophyll (HNLC) areas in the southern oceans and in the northeast Pacific subarctic (Martin \& Fitzwater 1988, Martin \& Gordon 1988, de Baar et al. 1990, Martin et al. 1991). Iron limitation has also been reported in coral reefs (Entsch et al. 1983) and in coastal waters (Glover 1978). This limitation is due to the low biological availability of iron and/or the very short residence times of bioavailable iron in surface waters, probably due to colloidal aggregation and/or sinking of larger particles containing iron (Martin et al. 1994).

\footnotetext{
·E-mail: sdengg@ifm.uni-kiel.d400.de
}

The chemical speciation of iron in seawater is poorly understood. Free available ferric ions are strongly hydrolysed in seawater, so that a substantial amount of iron in the dissolved pool may be in the colloidal form. Bioavailability is low for colloidal iron (Anderson \& Morel 1982, Rich \& Morel 1990, Wells et al. 1991); it can be increased by photoreduction or solubilisation (Rich \& Morel 1990, Johnson et al, 1994). Natural organic iron-specific complexing ligands in seawater may be in excess of the total dissolved iron concentrations (Gledhill \& van den Berg 1994). The organically complexed fraction of dissolved iron may thus have been underestimated up to now. The nature of these organic ligands has so far not been elucidated, but among these, siderophores may play an important role in maintaining iron in solution and making it available for biological uptake (Neilands 1974).

Siderophores are high-affinity iron complexing ligands produced and utilized by many microorganisms: in the marine environment by eubacteria (Goyne \& 
Carpenter 1974, Trick 1989, Reid \& Butler 1991, Haygood et al. 1993) and cyanobacteria (Murphy et al. 1976, Armstrong \& van Baalen 1979). Trick et al. (1983) found siderophore production among marine eukaryotic phytoplankton. In our experiments, we used a sensitive crossfeeding test to screen 20 freshwater and marine microalgae species for siderophore production, according to a method described in detail in Reissbrodt \& Rabsch (1988). None of the species tested exhibited positive results for endogenous siderophore production. We therefore propose that microalgae do not produce their own siderophores but may utilize exogenous siderophores produced by other microorganisms.

Siderophore production is an adaptation to low ambient iron concentrations; it is developed by quite a number of microorganisms (Neilands et al. 1987). Some bacterial strains have lost the ability to synthesize these substances but have retained the capacity to utilize siderophores released by other microorganisms (Luckey et al. 1972). Crowley et al. (1988) and Bar-ness et al. (1991) reported the utilization of microbial siderophores by higher plants, and Bailey \& Taub (1980) suggested that the freshwater green alga Chlorella vulgaris can utilize iron from the chelator, ferrioxamine B. This was verified by Allnutt \& Bonner (1987 a, b).

In this paper we report on the utilization of iron from microbial siderophores by marine microalgae. We focus on 2 hydroxamate-type siderophores, ferrioxamine $B$ (FOB) and ferrioxamine $E$ (FOE), since Trick (1989) reported widespread production of these types of siderophores among marine eubacteria. The results
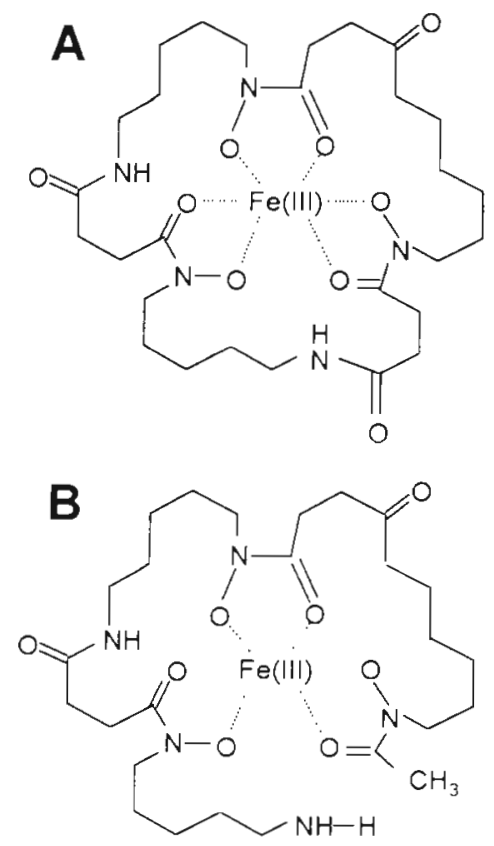

Fig. 1 Structure of $(A)$ ferrioxamine $E$ and $(B)$ ferrioxamine $B$ of the inhibition experiments where we employed bathophenanthroline disulfonic acid, BPDS, a strong $\mathrm{Fe}^{+2}$ chelator, demonstrate that these 2 siderophores, although similar in structure (Fig. 1), are taken up via different transport mechanisms. In addition, growth experiments were performed to show the efficiency of these siderophores as 'iron-suppliers' for phytoplankton.

This investigation introduces an alternative strategy by which phytoplankton acquire iron from the environment. It also provides a new perspective of the multifaceted bacteria-phytoplankton interaction.

\section{MATERIALS AND METHODS}

Materials. Desferrioxamine B (Desferal ${ }^{\circledR}$ ) and E as well as ferrioxamine E were gifts from the Ciba-Geigy Corp., Basel, Switzerland. Chelex 100 was obtained from Bio-Rad Laboratories and ${ }^{55} \mathrm{FeCl}_{3}$ in $0.1 \mathrm{mM} \mathrm{HCl}$ was acquired through Amersham Buchler, Braunschweig, Germany.

Bacterial strains used for the siderophore bioassay (Salmonella typhimurium enb-7, Aureobacterium flavescens JG-9 and Morganella morganii SBK3) were generously provided by Drs R. Reissbrodt and W. Rabsch of the Robert Koch Institute, Wernigerode Branch, Germany

Preparation of labelled complexes. Desferrioxamine $B$ (DFOB) and desferrioxamine $E$ (DFOE) as well as EDTA were labelled with ${ }^{55} \mathrm{Fe}$ using the method described by Müller \& Raymond (1984). DFOB and EDTA were dissolved in sterilized Milli-Q water and DFOE in $50 \%$ distilled methanol to give a $1 \mathrm{mM}$ stock solution. For the experiments $0.01 \mathrm{mM} \quad\left[{ }^{55} \mathrm{Fe}\right]-$ siderophore or $\left[{ }^{55} \mathrm{Fe}\right]-E D T A$ solutions with an activity of $5 \mu \mathrm{Ciml}^{-1}$ at $\mathrm{pH} 7$ were prepared. To ensure complete reaction between the chelators and ${ }^{55} \mathrm{Fe}$, the labelled complexes were prepared $12 \mathrm{~h}$ before the actual experiments

Preparation of medium. For all experiments, only polycarbonate flasks or polystyrene tubes were used to minimize $\mathrm{Fe}$ adsorption to container walls. Reusable containers were soaked in a $10 \% \mathrm{HCl}$ bath for at least $48 \mathrm{~h}$ and rinsed repeatedly with Milli-Q water. All flasks used were vapor sterilised; disposable tubes were obtained in sterile packages. Modified AQUIL medium (Morel et al. 1979) was used for all experiments and for the maintenance of algal cultures. Low nutrient Atlantic ocean seawater was filtered $(0.2 \mu \mathrm{m})$ and deferrated by passing through a Chelex $100 \mathrm{col}-$ umn. Nutrient solutions were prepared according to Morel et al. (1979) and deferrated in the same manner as the seawater. A metal solution as specified for AQUIL was prepared without the addition of EDTA 
and $\mathrm{FeCl}_{3}$. For the maintenance cultures Fe was prepared separately as an Fe-EDTA solution and was added to the medium to a final concentration of

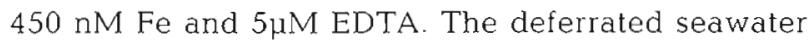
and the nutrient solutions were autoclaved separately in polycarbonate Erlenmeyer flasks at $120^{\circ} \mathrm{C}$ and 1 bar for $20 \mathrm{~min}$.

To test whether the medium was iron deficient, growth experiments were performed using Phaeodactylum tricornutum, Dunaliella bioculata and Anabaena sp. Fig. 2 shows the growth curves of these 3 microalgae in Fe-deficient (no iron added) and Fesufficient $(450 \mathrm{nM} F \mathrm{Fe}$ media. In the Fe-deficient medium, $P$. tricornutum and $D$. bioculata did not exhibit growth, while in the medium with $450 \mathrm{nM} \mathrm{Fe}$, chlorophyll concentrations increased in both species. Anabaena sp. showed growth in both treatments with lower chlorophyll values in the Fe-deficient medium.

To ensure enough cell harvest for the experiments, Fe was added at very low concentrations ( $10 \mathrm{nM})$ to the Fe-deficient cultures. To minimize the intracellular iron pools, 2 transfers were made within $7 \mathrm{~d}$. The last transfer was performed $1 \mathrm{~d}$ before the actual experiments and no iron was added to the culture medium. The cells were concentrated by centrifugation at $4000 \mathrm{rpm}$ for $15 \mathrm{~min}$ and by decanting the excess fluid.

Algal cultures. Stock cultures were obtained from the culture collection of the University of Göttingen, Germany. Phaeodactylum tricornutum, Dunaliella bioculata and Anabaena sp. were obtained as axenic cultures either in agar slants or fluid media. The cells were immediately transferred to the experimental medium. The sterile condition of the cultures was monitored regularly by acridine orange staining (Hobbie et al. 1977) or by obtaining inocculum from the cultures and introducing this onto agar media for marine bacteria. The plates were checked for bacterial growth after 24 and $48 \mathrm{~h}$. The stock cultures were maintained at $20^{\circ} \mathrm{C}$ with 10:14 h light/dark period.

Growth experiments. The growth of Phaeodactylum tricornutum, Dunaliella bioculata and Anabaena sp. was determined by measuring chl a. The growth of these species in Fe-deficient cultures in the presence and absence of bacteria was compared. Bacteria used were isolated from nonaxenic cultures of $P$. tricornutum, then grown in iron-deficient seawater medium. To ensure that the bacteria were producing siderophores prior to introduction to the non-axenic medium, these were tested using the microbial bioassay with Salmonella typhimurium enb-7 and Aureobacterium flavescens JG9 as indicator strains. The increase in chl a concentrations was measured for $P$. tricornutum in the presence of ferrated (FOE and FOB) and non-ferrated (DFOE and DFOB) siderophores. The final concentrations of $\mathrm{Fe}$ and siderophores were $450 \mathrm{n} \mathrm{M}$ and $5 \mu \mathrm{M}$,
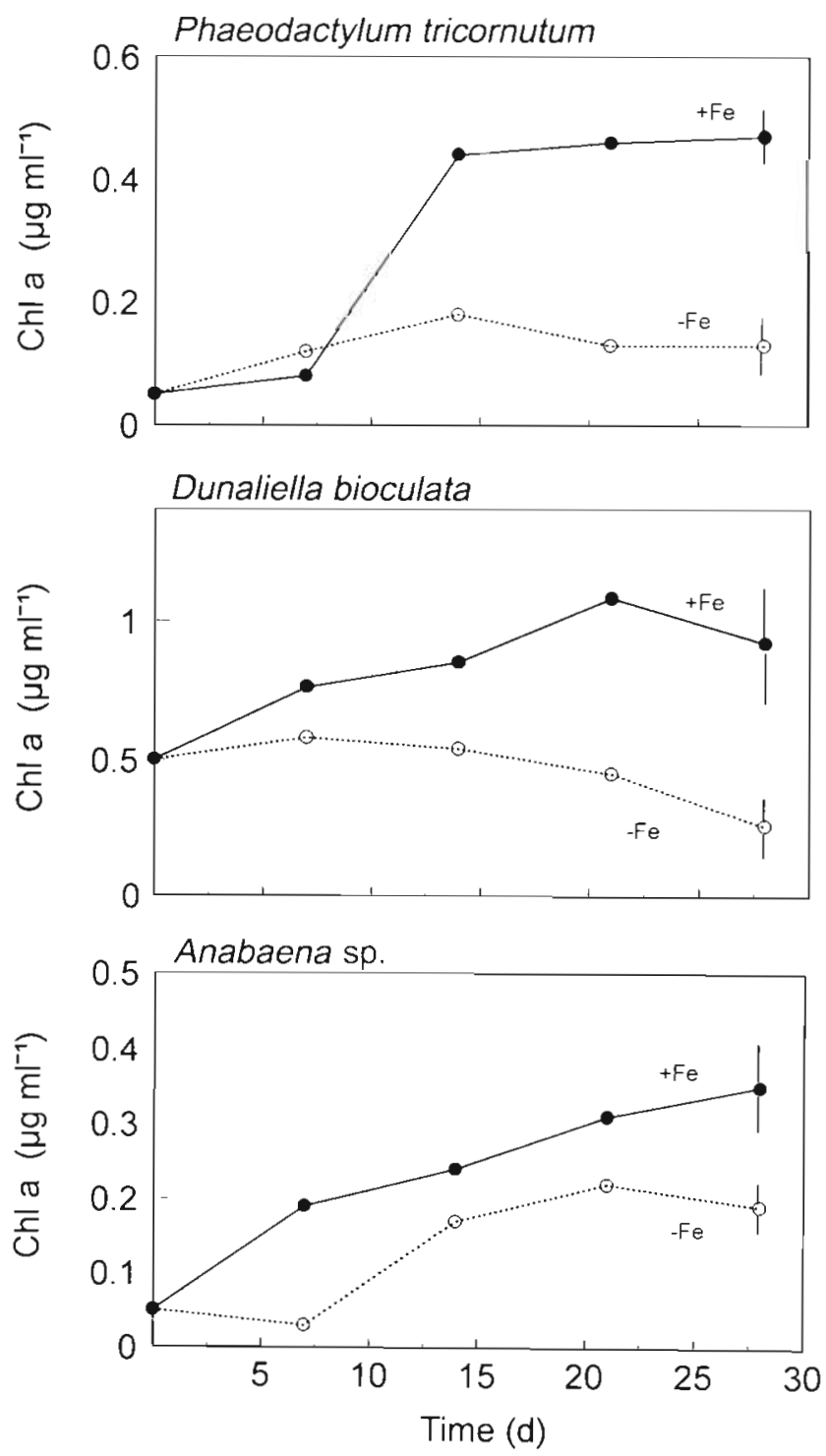

Fig. 2. Growth of axenic cultures of Phaeodactylum tricornutum, Dunaliella bioculata and Anabaena sp. measured as the increase of chl a concentration per ml culture sample over $28 \mathrm{~d}$. Results are presented as the means of 3 replicates with 1 SD on Day 28. (•) Fe added as Fe-EDTA (Fe 450 nM, EDTA $5 \mu \mathrm{M}),(0)$ no Fe added

respectively. All growth experiments were maintained for $28 \mathrm{~d}$ at $20^{\circ} \mathrm{C} 10: 14 \mathrm{~h}$ light/dark period. The axenic nature of the cultures was regularly monitored.

Test for siderophore production. To test siderophore production in the microalgae we used in our experiments, the universal siderophore assay (CAS) (Schwyn \& Neilands 1987) and the more specific and sensitive bacterial bioassays (Reissbrodt \& Rabsch 1988, Rabsch \& Winkelmann 1991) were employed. For the latter we used the following siderophore auxotrophic bacteria strains which indicate specific siderophore types: Salmonella typhimurium enb-7, hydroxamate- and phenolate- 
type siderophores; Aureobacterium flavescens JG9, other hydroxamates; and Morganella morganii SBK3, siderophores containing $\alpha$-keto/ $\alpha$-hydroxy-bidentate ligands (Thieken \& Winkelmann 1993). As controls, natural bacterial populations in seawater samples were grown in iron-deficient seawater media and then inoculated onto the bioassay plates.

Uptake and inhibition experiments. The uptake experiments were done in sterile $15 \mathrm{ml}$ polystyrene tubes with screw caps which were filled with $5 \mathrm{ml}$ of the sterile medium. Unless otherwise specified, ${ }^{55} \mathrm{Fe}$-ferrioxamine or ${ }^{55} \mathrm{Fe}$-EDTA was added to a final concentration of $0.4 \mu \mathrm{M}$. Unchelated ${ }^{55} \mathrm{Fe}$ was added at the same concentration as that of the iron chelated to EDTA or the siderophores. To determine the nature of ferrioxamine as Fe supplier to phytoplankton, Fe-starved and Fesufficient cells were used. The cells were incubated for $20 \mathrm{~h}$ under the same conditions as the maintenance cultures. After incubation, the cells were filtered onto nitrate cellulose filters $(0.45 \mu \mathrm{m})$ which were previously soaked for $24 \mathrm{~h}$ in $1 \mathrm{mM}$ EDTA with $\mathrm{pH} 5$. The $\mathrm{TiCl}_{3}$-EDTA-wash method described by Hudson \& Morel (1989) for eliminating adsorbed iron was employed. The filters with cells were placed in filter-count scintillation fluid and counted with a Hewlett-Packard scintillation counter. All experiments were repeated once; each treatment was done in triplicate.

For the transport and inhibition experiments, only Fe-limited Phaeodactylum tricornutum was used and incubation was $3 \mathrm{~h}$ in the light. The time dependent uptake was determined by adjusting the incubation times to $30,60,90,120,150$ and $180 \mathrm{~min}$ and concentration-dependent uptake was measured by adding the Fe-ferrioxamine complex in concentrations ranging from 0.1 to $4.0 \mu \mathrm{M}$.

For transport inhibition, bathophenanthroline-disulfonic acid (BPDS), a strong $\mathrm{Fe}^{+2}$ chelator, was added at $0,0.2,0.4,0.8,1.2$ and $1.6 \mu \mathrm{M}$ to give BPDS:Fesiderophore molar ratios of $0,0.5,1,2,3$ and 4 , respectively. The cells were prepared as described above for the ${ }^{55}$ Fe-uptake measurement.

\section{RESULTS}

\section{${ }^{55} \mathrm{Fe}$ uptake from ferrioxamines}

Our results demonstrate that the diatom, Phaeodactylum tricornutum, and the cyanobacterium, Anabaena sp., grown in iron-deficient medium were able to take up iron from one or both of the hydroxamate siderophores, whereas Dunaliella bioculata showed minimal iron uptake from both siderophores (Table 1). The data also show that iron was taken up from FOE more efficiently by about $50 \%$ than from FOB in $P$. tri-
Table 1 Iron uptake by Phaeodactylum tricornutum, Dunaliella bioculata and Anabaena sp. grown under iron deficient conditions. Values are the means of 3 replicates $\pm \mathrm{SD}$

\begin{tabular}{|lccc|}
\hline \multirow{2}{*}{$\begin{array}{c}\text { Source of iron } \\
\end{array}$} & \multicolumn{3}{c|}{ Iron uptake (pg Fe $\mathrm{mg}^{-1}$ ) } \\
& P.tricornutum & D. bioculata & Anabaena \\
\hline $\mathrm{FeCl}_{3}$ & $58 \pm 12$ & $79 \pm 13$ & $71 \pm 19$ \\
$\mathrm{Fe}-\mathrm{EDTA}$ & $26 \pm 6$ & $57 \pm 2$ & $53 \pm 14$ \\
$\mathrm{FOE}$ & $117 \pm 2$ & $28 \pm 2$ & $42 \pm 8$ \\
$\mathrm{FOB}$ & $68 \pm 5$ & $36 \pm 11$ & $88 \pm 8$ \\
\hline
\end{tabular}

Table 2. Iron uptake by Phaeodactylum tricornutum, Dunaliella bioculata and Anabaena sp. grown under iron sufficient conditions. Values are the means of 3 replicates \pm SD

\begin{tabular}{|c|c|c|c|}
\hline \multirow[t]{2}{*}{ Source of iron } & \multicolumn{3}{|c|}{ Iron uptake (pg Fe $\mathrm{mg}^{-1}$ ) } \\
\hline & P. tricornutum & D. bioculata & Anabaena \\
\hline $\mathrm{FeCl}_{3}$ & $30 \pm 9$ & $23 \pm 9$ & $16 \pm 2$ \\
\hline Fe-EDTA & $27 \pm 3$ & $18 \pm 5$ & $18 \pm 1$ \\
\hline FOE & $11 \pm 3$ & $6 \pm 0.2$ & $8 \pm 0.8$ \\
\hline $\mathrm{FOB}$ & $9 \pm 4$ & $3 \pm 1$ & $9 \pm 1$ \\
\hline
\end{tabular}

cornutum. Fe uptake from FOE by iron-deficient $P$. tricornutum was higher than from $\mathrm{FeCl}_{3}$ or $\mathrm{Fe}$-EDTA. On the other hand, utilization of iron from $\mathrm{FOB}$ and $\mathrm{FeCl}_{3}$ seemed to be comparable in both $P$. tricornutum and Anabaena sp.

Apparently, Fe from ferrioxamines is taken up only by Fe-limited cells since Fe-uptake from the siderophores is greatly reduced when the cells are not starved for iron (Table 2). Iron-sufficient cells took up $\mathrm{Fe}$ from $\mathrm{FeCl}_{3}$ and Fe-EDTA more readily compared to the ferrioxamines, although uptake from these sources was higher in iron-limited cells.

\section{Mechanism of Fe uptake from ferrioxamines}

Since Phaeodactylum tricornutum exhibited uptake from both FOE and FOB, it was used in the succeeding experiments. Iron uptake from the ferrioxamines proceeded linearly with time for $3 \mathrm{~h}$ of incubation (Fig 3). The rate of $\mathrm{Fe}$ uptake was generally higher for FOE than for FOB.

Concentration dependent Fe uptake from FOE and FOB is shown in Fig. 4. Apparently, a saturable system is involved in the transport of iron into the cell. Calculation of the $\mathrm{K}_{\mathrm{m}}$ through a Lineweaver-Burke transformation gave values of 0.4 and $0.9 \mu \mathrm{M}$ for FOE and $F O B$, respectively, indicating a higher affinity of the transport mechanism for FOE than for $F O B$.

BPDS is a strong $\mathrm{Fe}^{+2}$ chelator and the Fe-BPDS complex is soluble and stable. BPDS was added to the 


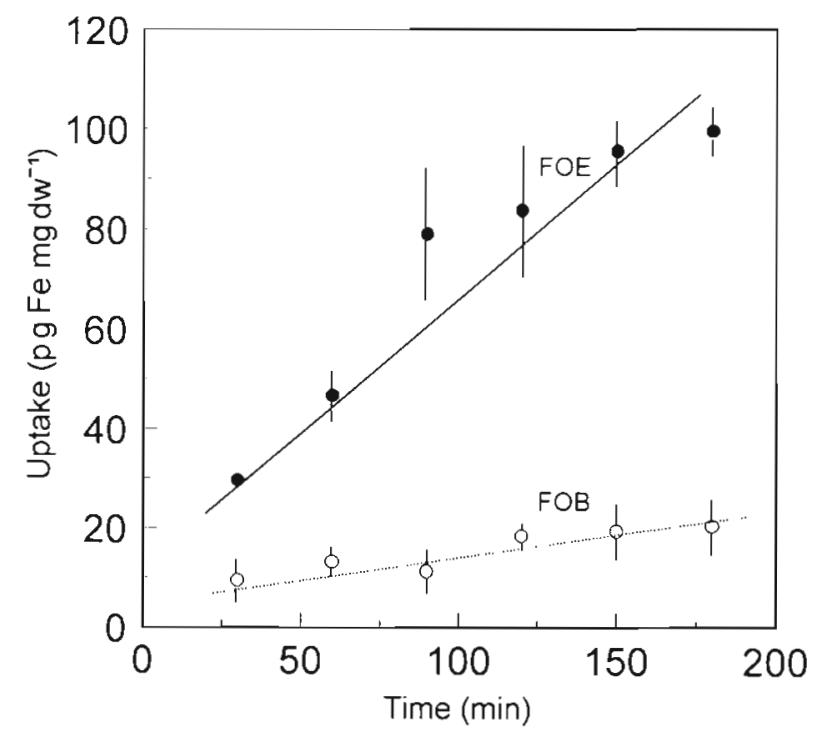

Fig. 3. Time dependent iron uptake by Phaeodactylum tricornutum from FOE ( ) and FOB (O). Fe-siderophore complex was added to a final concentration of $0.4 \mu \mathrm{M}$. Results are presented as means of 6 replicates

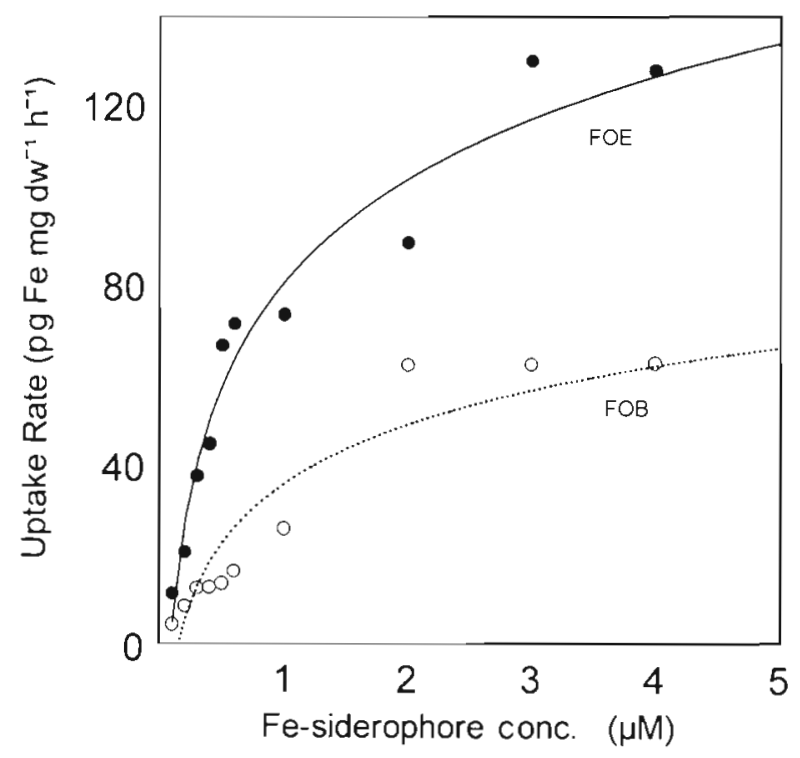

Fig. 4. Concentration dependent kinetics of iron uptake from FOE ( ) and FOB (O) by Phaeodactylum tricornutum. Results are presented as means of 6 replicates

culture medium in different molar concentrations to test whether an obligatory reduction step is involved in the uptake of Fe from ferrioxamines. BPDS had varying effects on ${ }^{55} \mathrm{Fe}$ uptake from ferrioxamines by Phaeodactylum tricornutum. Increasing BPDS concentrations led to increasing uptake inhibition from FOB but not from FOE (Fig. 5). This result suggests that

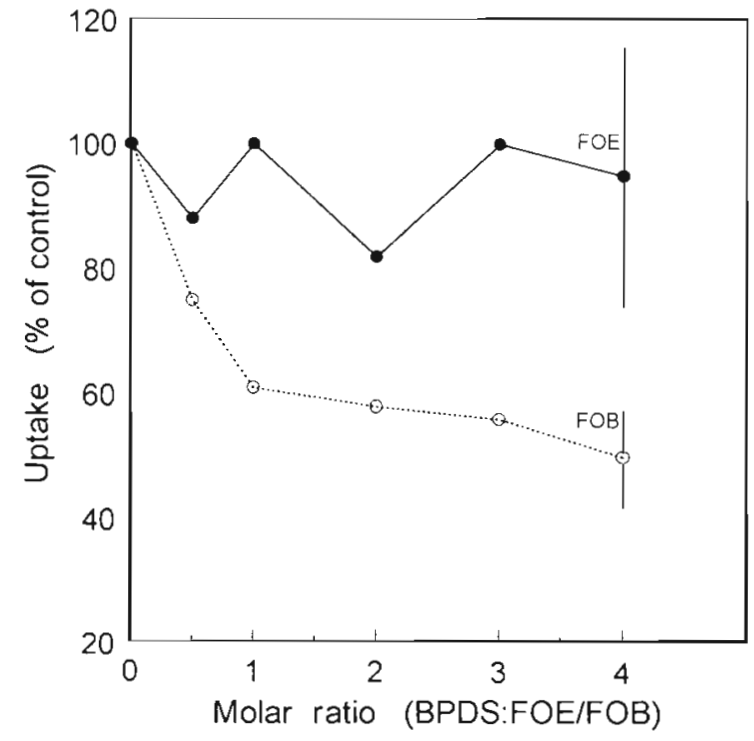

Fig. 5. Iron uptake by Phaeodactylum tricornutum from FOE $(\bullet)$ and FOB $(O)$ with the addition of different concentrations of BPDS given as the molar ratio of BPDS to the metalsiderophore complex. Uptake is presented as percentage of the control (no BPDS added). Results are the means of 6 replicates with 1 SD at BPDS:siderophore ratio of 4

iron from the 2 ferrioxamines is taken up via different mechanisms. For FOB extracellular reduction is probably a necessary prerequisite for Fe transport into the cell, whereas for FOE it seems that the cell is capable of internalizing the intact metal-siderophore complex.

\section{Growth experiments}

The growth of microalgae in iron-limited medium in the presence and absence of bacteria showed increased chl a concentrations for Phaeodactylum tricornutum and Anabaena sp. in the nonaxenic cultures (Fig. 6). These are the species which also exhibited iron utilization from the hydroxamate siderophores. This may be an indication that the siderophores produced by the bacteria introduced into the medium were capable of solubilizing residual iron in the medium, which subsequently could have been utilized by the microalgae. Indeed, we tested the bacteria in the cultures at the end of the experiments for siderophore production and these yielded positive results for the CAS assay and for the crossfeeding tests with Salmonella typhimurium enb- 7 and Aureobacterium flavescens JG-9 (both indicating hydroxamate siderophore production). However, the possibility that the bacteria also produced other growth promoting substances for the microalgae should not be excluded. Dunaliella bioculata, which can not uti- 

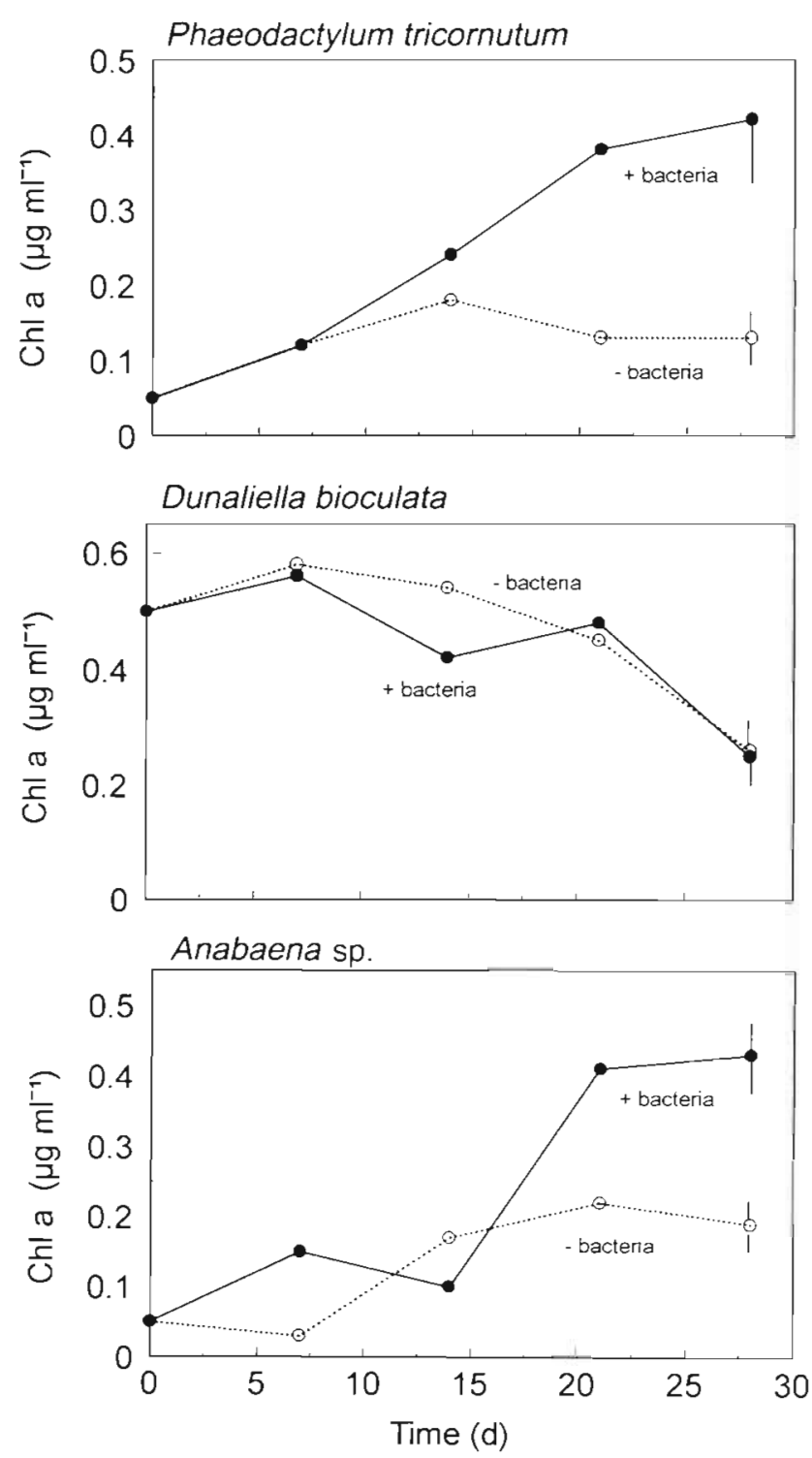

Fig. 6. Growth of Phaeodactylum tricornutum, Dunaliella bioculata and Anabaena sp. in axenic (O) and nonaxenic ( media measured as the increase in chl a concentration per $\mathrm{ml}$ culture sample over $28 \mathrm{~d}$. No iron was added to the culture media. Results are presented as the means of 3 replicates with $1 \mathrm{SD}$ on Day 28

lize iron from the ferrioxamines, did not grow in the Fe-limited medium under either axenic or nonaxenic conditions

Phaeodactylum tricornutum also exhibited growth comparable to cultures where $\mathrm{Fe}$ was added as FeEDTA when FOE or FOB was added as iron source for the cells (Figs. $2 \& 7$ ). The chl a maximum was reached on Day 14 for the FOB treatment. With FOE in the medium comparable chl a concentrations were reached on Day 22. Addition of nonferrated siderophores (DFOE \& DFOB) also led to increased chl a concentra- tions in this species, although to a lower extent when compared to the addition of FOE and FOB.

\section{Siderophore production in microalgae}

Both CAS assay and the microbial bioassay for siderophores showed negative results for Phaeodactylum tricornutum and Dunaliella bioculata. The cyanobacterium, Anabaena sp., showed a positive assay for the CAS plates and could crossfeed Salmonella typhimurium enb- 7 and Aureobacterium flavescens JG-9, indicating the production of utilizable hydroxamate-type siderophores. Other species of marine and freshwater microalgae, including several species of Dunaliella, Tetraselmis, Cyclotella and Chlorella were also tested for siderophore production, but none showed positive for the CAS assay or the bioassay (data not shown). Slight acidification of the medium was however observed through a characteristic discoloration of the CAS agar around the inocculum.

The negative results obtained from the siderophore assays served as a control that the uptake data obtained in the preceeding experiments were due to the introduced microbial hydroxamates and not from siderophores excreted by the microalgae.

\section{DISCUSSION}

In this study we showed that Phaeodactylum tricornutum is capable of utilizing iron from the microbial trihydroxamate-type siderophores, ferrioxamine B and ferrioxamine $E$. The utilization of iron from exogenous siderophores by marine microalgae as a strategy for sequestering this essential element from the medium has not been reported so far. Ferrioxamine B and E were capable of supplying the diatom with iron only when the cells were grown in iron-deficient conditions. This indicates that iron limitation induces the cell to produce substances or to activate transport systems which enable it to avail of the iron bound to the siderophores. Our results provide evidence that these substances are siderophore specific and that there exists a multiple-pathway mechanism for iron uptake from foreign siderophores.

The decrease of iron uptake from FOB with BPDS treatment strongly suggests that an extracellular reductive mechanism is involved, probably the ratedetermining process in the utilization of iron from $F O B$ by Phaeodactylum tricornutum. A reductive mechanism was demonstrated for iron uptake from FOB by Chlorella vulgaris (Allnutt \& Bonner 1987b). The reduction of the ferric ion bound to the siderophore is apparently membrane associated. Finden et al. (1984) 


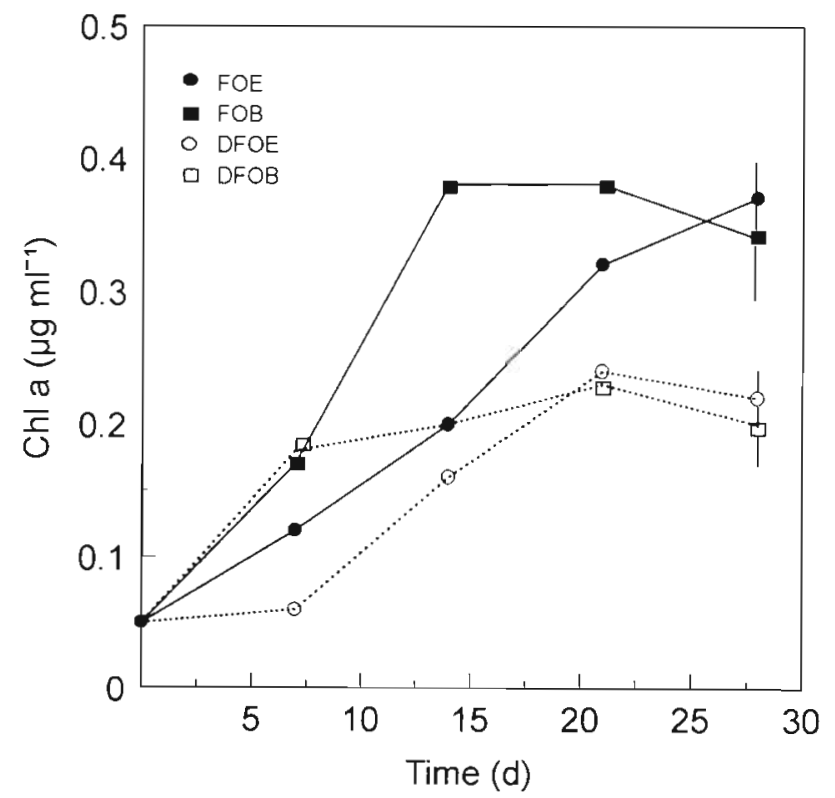

Fig. 7. Growth of axenic cultures of Phaeodactylum tricornutum measured as the increase in chl a concentration per $\mathrm{ml}$ culture sample over $28 \mathrm{~d}$. Siderophores were added at a concentration of $5 \mu \mathrm{M}$ as ferrated [FOE (๑) and FOB (a)] and nonferrated [DFOE $(O)$ and DFOB $(\square)]$ ferrioxamines. The concentration of $\mathrm{Fe}$ in $\mathrm{FOE}$ and FOB was $450 \mathrm{nM}$. The results are presented as the means of 3 replicates with 1 SD on Day 28

found no Fe-BPDS complexation with ferrioxamine B in photochemical experiments, i.e. in cultures without cells. Furthermore, external ferric reductants like ascorbate did not reduce FOB (Anderson \& Morel 1982). Complete inhibition of iron uptake from FOB by BPDS was not observed. This can be explained by the inability of the chelator to compete effectively with the cell for the ferrous ion. Another possibility is that the deferrated siderophore can react with $\mathrm{Fe}(\mathrm{II})$ itself interfering with the complete reaction of $\mathrm{Fe}(\mathrm{II})$ with BPDS (Hudson et al. 1992).

The involvement of a reductive mechanism for iron uptake is common among organisms. It has been reported for higher plants (Chaney et al. 1972), bacteria (Reissbrodt 1994) and yeast cells (Lesuisse \& Labbe 1992). In phytoplankton, the presence of plasmalemma redox enzymes and their importance for iron uptake are well documented (Jones et al. 1987). However, the reductive systems involved in the iron uptake from FOB and Fe-EDTA in Phaeodactylum tricornutum seem to be different. FOB supplies iron to cells grown under Fe-deficient conditions more effectively than Fe-EDTA (Table 1). Considering the reduction potentials of both complexes (+94 $\mathrm{mV}$ for Fe-EDTA and -468 $m V$ for $F O B$ ) and if the 2 iron chelators are acted upon by the same reductases, Fe-EDTA should be preferably reduced compared to FOB. Besides, for a signifi- cant reduction to occur, the reduction potential of the metal complex should exceed that of the redox enzyme which has a potential between $-100 \mathrm{mV}$ and $+94 \mathrm{mV}$ (Jones et al. 1987). Thus there may be another set of enzymes produced by the cell responsible for the reduction of $\mathrm{FOB}$.

Ferrioxamine $E$, although similar in structure to $F O B$, is transported by the cell via a different mechanism. Our results suggest that the entire metal-siderophore complex was taken up since no significant inhibition was observed upon addition of BPDS. Unfortunately, no ${ }^{14} \mathrm{C}$-labelled siderophores could be obtained so that we could not follow the fate of FOE. It seems that FOE is taken up via a 'true-siderophore' uptake system where reduction of the bound iron occurs intracellularly. This type of uptake is similar to that observed for Streptomyces pilosus, which produces both ferrioxamine $\mathrm{B}$ and $\mathrm{E}$, and where both siderophores are taken up via the same uptake system (Müller \& Raymond 1984). This is based on the recognition of the hydroxamate iron center and its direct surroundings (Müller et al. 1984). For Phaeodactylum tricornutum, however, a different system may be involved because only FOE and not FOB can be transported as a metal-siderophore complex. Further studies are necessary to better understand ferrioxamine mediated iron transport in marine eukaryotic microalgae.

The iron uptake mechanisms for FOB and FOE are saturable. For FOB, saturation would coincide with the saturation of the enzymes responsible for the reduction of iron. For FOE this would indicate the saturation of the transport ligands. For both reductive and 'truesiderophore' uptake, saturation of the systems has been commonly observed (Müller \& Raymond 1984, Jones et al. 1987). The $K_{\mathrm{m}}$ values (half-saturation concentrations) calculated for the 2 ferrioxamines studied indicate that FOE provides the cell with iron more efficiently than FOB. However, the growth curves of Phaeodactylum tricornutum in the presence of ferrioxamines do not support this. The case of iron uptake from FOE and FOB by $P$. tricornutum may be analogous to the case of ferrichrome and ferrichrome A in Ustilago sphaerogena. This basidiomycetous fungus produces both siderophores but ferrichrome is taken up via the 'true-siderophore' uptake system whereas ferrichrome A requires a reductive system (Emery 1987). Ferrichrome A however is more efficient in supplying iron to the cell since this is supplied as utilizable $\mathrm{Fe}^{+2}$. On the other hand, ferrichrome must still be reduced intracellularly and if this reduction in the cytoplasm is slow, then the iron is not readily available to the cell. The growth curves of $P$. tricornutum strongly suggest that this might be what happened within the cells during our study. FOB supplied iron as $\mathrm{Fe}^{+2}$ to the cells, making it readily available for assimilation, whereas FOE 
may still have undergone a slow intracellular reduction so that a delay occurred before iron could be utilized for cellular processes

The importance of microbial siderophores as source of iron for marine phytoplankton must be further explored. Hudson \& Morel (1990) have provided unequivocal evidence that a high affinity transport is possible in Fe-limited phytoplankton without the exudation of siderophores. However, the presence of microbial siderophores in the medium should present the phytoplankton cells with an alternative source of this essential element. This would find relevance in Fe-limited systems in the oceans, where bacteria may be producing siderophores (Goyne \& Carpenter 1974 Trick 1989, Reid \& Butler 1991, Haygood et al. 1993) As we observed in our crossfeeding experiments, a majority of the phytoplankton we tested does not produce their own siderophores. The microalgae may nevertheless be equipped with mechanisms to avail of those produced by other microorganisms. They share this ability with a number of bacteria which have lost the ability to produce these substances but are able to sequester iron from exogenous siderophores (Luckey et al. 1972, Rabsch \& Winkelmann 1991).

The affinity of the Phaeodactylum tricornutum FOEuptake system is admittedly lower than that of Streptomyces pilosus which produces this substrate $\left(K_{\mathrm{m}} \approx\right.$ 0.2 uM) (Müller \& Raymond 1984). Thus for siderophores to be ecologically relevant for phytoplankton, the microalgae should be able to compete with bacteria for iron acquisition from these substances. Some bacteria, however, show higher uptake rates for foreign siderophores than for their own self-produced siderophores. S. pilosus, for example, takes up exogenous hydroxamates like ferrichrome and ferrichrysin faster than their native ferrioxamines $B$ and $E$ (Müller et al. 1984). Thus microorganisms may produce siderophores which they may not utilize at all if other siderophores for which they have a higher affinity are present in the environment, leaving their own siderophores available for utilization by other organisms. Furthermore, the uptake systems for ferrisiderophores in bacteria are saturable, so that there may be excess siderophores in the medium for phytoplankton uptake. More studies will be necessary to better understand this new aspect of bacteria-phytoplankton interaction.

Acknowledgements. We thank Drs. R. Reissbrodt, U. Sommer and J. C. Duinker for reading and contributing to the improvement of the manuscript. Ms. R. Krehl and Ms. C. Eggert provided expert technical assistance. Financial support was obtained from the Centre Europeen D'Etudes des Polyphosphates E.V. (CEEP) and from the EU-Environment MARE Project.

\section{LITERATURE CITED}

Allnutt FCT, Bonner WD (1987a) Characterization of iron uptake from ferrioxamine B by Chlorella vulgaris. Plant Physiol 85:746-750

Allnutt FCT, Bonner WD (1987b) Evaluation of reductive release as a mechanism for iron uptake from ferrioxamine B by Chlorella vulgaris. Plant Physiol 85:751-756

Anderson MA, Morel FMM (1982) The influence of aqueous iron chemistry on the uptake of iron by the coastal diatom Thalassiosira weissflogii. Limnol Oceanogr 27: $789-813$

Armstrong JE, van Baalen C (1979) Iron transport in microalgae: the isolation and biological activity of a hydroxamate siderophore from the blue-green alga Agmenellum quadruplicatum. J gen Microbiol 111:253-262

Bailey KM, Taub FB (1980) Effects of hydroxamate siderophores (strong Fe(III) cielators) on the growth of algae. J Phycol 16:334-339

Bar-ness E, Chen Y, Hadar Y, Marschner H, Römheld V (1991) Siderophores of $P_{\text {seudomonas putida as an iron source for }}$ dicot and monocot plants. Plant Soil 130:231-241

Chaney RL. Brown JC, Tiffin LO (1972) Obligatory reduction of ferric chelates in iron uptake by soybeans. Plant Physiol 50:208-213

Crowley DE. Reid CPP, Szanislo PJ (1988) Utilization of microbial siderophores in iron acquisition by oat. Plant Physiol 87:680-685

De Baar HJW, Buma AGJ, Nolting RF, Cadee GC, Jacques G, Trequer PJ (1990) On iron limitation of the Southern Ocean: experimental observations in the Weddell and Scotia Seas. Mar Ecol Prog Ser 65:105-122

Emery $T$ (1987) Reductive mechanisms of iron assimilation. In: Winkelmann G, van der Helm D, Neilands JB (eds) Iron transport in microbes, plants and animals. $V \mathrm{CH}$, Weinheim, p 236-250

Entsch B, Sim RG, Hatcher BG (1983) Indications from photosynthetic components that iron is a limiting nutrient in primary producers on coral reefs. Mar Biol 73 : $17-30$

Finden DAS, Tipping E, Jaworski GHM, Reynolds CS (1984) Light-induced reduction of natural iron (III) oxide and its relevance to phytoplankton. Nature 309:783-784

Gledhill $M$, van den Berg CMG (1994). Determination of complexation of iron (III) with natural organic complexing ligands in seawater using cathodic stripping voltammetry. Mar Chem 47:41-54

Glover H (1978) Iron in Maine coastal waters; seasonal variation and its apparent correlation with a dinoflagellate bloom. Limnol Oceanogr 23:534-537

Goyne ER, Carpenter EJ (1974) Production of iron-binding compounds by marine micro-organisms. Limnol Oceanogr 19:840-842

Haygood MG, Holt PD, Butler A (1993) Aerobactin production by planktonic marine Vibrio. Limnol Oceanogr 35 $1002-1020$

Hobbie JE, Daley RJ, Jasper S (1977) Use of nucleopore filters for counting bacteria by fluorescence microscopy. Appl environ Microbiol 33:1225-1228

Hudson R, Morel FMM (1989) Distinguishing between extraand intracellular iron in marine phytoplankton. Limnol Oceanogr 34:1113-1120

Hudson R, Morel FMM (1990) Iron transport in marine phytoplankton: kinetics of cellular medium co-ordination reactions. Limnol Oceanogr 35:1002-1020

Hudson RJM, Covault DT, Morel FMM (1992) Investigation of iron co-ordination and redox reactions in seawater 
using ${ }^{59} \mathrm{Fe}$ radiometry and ion-pair solvent extraction of amphiphilic iron complexes. Mar Chem 38:209-235

Johnson KS, Coale KS, Elrod VA, Tindale NW (1994) Iron photochemistry in seawater from the equatorial Pacific Mar Chem 46:319-334

Jones GJ, Palenik BP, Morel FMM (1987) Trace metal reduction: the role of plasmalemma redox enzymes. J Phycol 23 $237-244$

Kolber ZS, Barber RT, Coale KH, Fitzwater SE, Greene RM, Johnson KS, Lindley S, Falkowski PG (1994) Iron limitation of phytoplankton photosynthesis in the equatorial Pacific Ocean. Nature 371: 145-149

Lesuisse E, Labbe P (1992) lron reduction and trans-plasma membrane electron transfer in the yeast Saccharomyces cerevisiae. Plant Physiol 100: 769-777

Luckey M, Pollack JR, Wayne R, Ames BN, Neilands JB (1972) Iron uptake in Salmonella typhimurium: utilization of exogenous siderochromes as iron carriers. J Bacteriol 111:731-738

Martin JH, Coale KH, Johnson KS, Fitzwater SE, Gordon RM and others (1994) Testing the iron hypothesis in ecosystemis of the equatorial Pacific Ocean. Nature 371:123-129

Martin JH, Fitzwater SE (1988) Iron deficiency limits phytoplankton growth in the northeast Pacific subarctic. Nature 331:341-343

Martin JH, Gordon RM (1988) Northeast Pacific iron distribution in relation to phytoplankton productivity. Deep Sea Res 35:177-196

Martin JH, Gordon RM, Fitzwater SE (1991) A case for iron. Limnol Oceanogr 36:1793-1802

Morel F, Reuter JG, Anderson DM, Guillard RRL (1979) AQUIL: a chemically defined phytoplankton culture medium for trace metal studies. J Phycol 15:135-141

Müller G, Matzanke BF, Raymond KN (1984) Iron transport in Streptomyces pilosus mediated by ferrichrome siderophores, rhodotorulic acid, and enantio-rhodotoluric acid. J Bacteriol 160:313-318

Müller G, Raymond KN (1984) Specificity and mechanism of ferrioxamine-mediated iron transport in Streptomyces pilosus. J Bacteriol 160:304-312

This article was presented by G. Rheinheimer (Senior Editorial Advisor), Kiel, Germany
Murphy TP, Lean DRS, Nalewajko C (1976) Blue-green algae: their excretion of iron-selective chelators enables them to dominate other algae. Science 192:900-902

Neilands JB (1974) Microbial iron transport compounds (siderochromes). In: Eichorn GL (ed) Inorganic biochemistry. Elsevier Scientific Publishing Co., New York, p167-202

Neilands JB, Konopka K, Schwyn B, Coy M, Francis RT, Paw $\mathrm{BH}$, Bagg A (1987) Comparative biochemistry of microbial iron assimilation In: Winkelmann G, van der Helm D, Neilands JB (eds) Iron transport in microbes, plants and animals. VCH, Weinheim, p 3-34

Rabsch W, Winkelmann G (1991) The specificity of bacterial siderophore bioassays. Biol Metals 4:244-250

Reid RT, Butler A (1991) Investigation of the mechanism of iron acquisition by the marine bacterium Alteromonas luteoviolaceus: characterization of siderophore production. Limnol Oceanogr 36:1783-1792

Reissbrodt R (1994) Iron and micro-organisms. Culture 15:5-8

Reissbrodt R, Rabsch W (1988) Further differentiation of enterobacteriaceae by means of siderophore-pattern analysis. Zentralbl Bakteriol Hyg A 268:306-317

Rich HW, Morel FMM (1990) Availability of well-defined iron colloids to the marine diatom Thalassiosira weissflogii. Limnol Oceanogr 35:652-662

Schwyn B, Neilands JB (1987) Universal chemical assay for the detection and determination of siderophores. Analyt Biochem 160:47-56

Thieken A, Winkelmann G (1993) A novel bioassay for the detection of siderophores containing keto-hydroxy bidentate ligands. FEMS Microbiol Lett 111:281-286

Trick CG (1989) Hydroxamate-siderophore production and utilization in marine eubacteria. Cur Microbiol 18: 375-378

Trick CG, Andersen RJ, Price NM, Gillam A, Harrison PJ (1983) Examination of hydroxamate siderophore production by neritic eukaryotic marine phytoplankton. Mar Biol 75:9-17

Wells ML, Mayer LM, Guillard RRL (1991) A chemical method for estimating the availability of iron to phytoplankton in seawater. Mar Chem 33:23-40

Manuscript first received: January 11, 1995

Revised version accepted: May 8, 1995 